\title{
Quantum Chemical Studies on the Corrosion Inhibition of Mild Steel by Piperidin-4-One Derivatives in $1 \mathrm{M} \mathrm{H}_{3} \mathrm{PO}_{4}$
}

\author{
Kalaiselvi Kathirvel ${ }^{1}$, Brindha Thirumalairaj ${ }^{2}$, Mallika Jaganathan ${ }^{2 *}$ \\ ${ }^{1}$ Department of Chemistry, PSGR Krishnammal College for Women, Coimbatore, India \\ ${ }^{2}$ Department of Chemistry, PSG College of Arts and Science, Coimbatore, India \\ Email: impsgcas@gmail.com
}

Received 22 August 2014; revised 22 September 2014; accepted 21 October 2014

Copyright (C) 2014 by authors and Scientific Research Publishing Inc.

This work is licensed under the Creative Commons Attribution International License (CC BY). http://creativecommons.org/licenses/by/4.0/

(c) (i) Open Access

\begin{abstract}
The corrosion inhibition properties of 2,6-diphenylpiperidin-4-one (DPP) (1A) and 2,6-diphenyldihydro-2H-thiopyran-4(3H)-one (DPDT) (1B) for mild steel in $1 \mathrm{M}$ phosphoric acid were studied using weight loss, potentiodynamic polarization and electrochemical impedance spectroscopic techniques. The effect of temperature on the corrosion behavior of mild steel has been examined in the temperature range $303-328 \mathrm{~K}$. The inhibition efficiency increases with increasing inhibitor concentration but decreases with increasing temperature. Potentiodynamic polarization studies indicated the mixed nature of inhibitors. The adsorption of the inhibitors on mild steel surface obeyed the Langmuir adsorption isotherms. The density functional theory (DFT) at the B3LYP/631G (d) basis set level was performed on $1 \mathrm{~A}$ and $1 \mathrm{~B}$ to investigate the correlation between molecular structure and the corresponding inhibition efficiency $(\%)$. The quantum chemical parameters such as $E_{\text {номо, }} E_{L U м о}$, the energy gap $(\triangle E)$, hardness $(\eta)$, softness $(S)$, dipole moment $(\mu)$, electron affinity $(A)$, ionization potential $(I)$, the absolute electronegativity $(\chi)$, the fraction of electron transferred $(\triangle N)$, electrophilicity index $(\omega)$, the back-donation $\left(\triangle E_{\text {Back-donation }}\right)$ and Mulliken population analysis have been calculated.
\end{abstract}

\section{Keywords}

2,6-Diphenylpiperdin-4-One Derivatives, Corrosion, Mild Steel, Phosphoric Acid, Density Functional Theory (DFT)

\section{Introduction}

The protection of metal surface against corrosion is an important industrial and scientific topic. Several ap-

${ }^{*}$ Corresponding author.

How to cite this paper: Kathirvel, K., Thirumalairaj, B. and Jaganathan, M. (2014) Quantum Chemical Studies on the Corrosion Inhibition of Mild Steel by Piperidin-4-One Derivatives in $1 \mathrm{M} \mathrm{H}_{3} \mathrm{PO}_{4}$. Open Journal of Metal, 4, 73-85.

http://dx.doi.org/10.4236/ojmetal.2014.44009 
proaches have been suggested and implemented to protect metals from the effect of corrosion. Among these approaches the use of corrosion inhibitors is the most common. Corrosion inhibitors are substance that when adsorbed onto the metal-solution interface (through either physisorption or chemisorption) blocks the corrosive material (solution) from coming into contact with metal. A number of heterocyclic compounds containing nitrogen, oxygen and sulphur either in the aromatic or in long chain carbon system have been reported to be effective inhibitors [1]. Recently, there has been increasing use of the density functional theory (DFT) methods as a theoretical tool in elucidating the mechanism of corrosion inhibition of heterocyclic organic compounds by several researchers [2]-[5]. Quantum chemical methods have already proven to be very useful in determination of the molecular structure as well as elucidating the electronic structure and reactivity.

\section{Experimental Methods}

The mild steel sheet $(\mathrm{C}=0.2 \%, \mathrm{Mn}=1.0 \%, \mathrm{P}=0.25 \%, \mathrm{~S}=0.025 \%$ and Rest $=\mathrm{Fe}$ ) was mechanically press-cut into specimens of dimension $2.5 \mathrm{~cm} \times 1 \mathrm{~cm} \times 0.05 \mathrm{~cm}$ and used for the weight loss measurements. For electrochemical methods, the working electrode is made of mild steel rod of same composition inserted in a Teflon tube with an exposed area of $0.1257 \mathrm{~cm}^{2}$. The specimens were polished with 320, 400 and 600 grit of emery sheets, washed with distilled water, degreased in acetone and dried in room temperature. The inhibitors used for the study were synthesized by the reported procedure [6].

\subsection{Weight Loss Method}

Gravimetric measurements were performed on mild steel coupons with the above mentioned dimensions in $1 \mathrm{M}$ $\mathrm{H}_{3} \mathrm{PO}_{4}$ solution with and without of inhibitors. Every sample was weighted by an electronic balance, and then placed in the acid solution $(100 \mathrm{~mL})$. The duration of the immersion was $2 \mathrm{hr}$ at the temperature range from 303 to $328 \mathrm{~K}$. After immersion, the surface of the specimens was cleaned by distilled water, dried and weighed in order to calculate the corrosion rate (CR) and inhibition efficiencies (\%). For each experiment, a freshly prepared solution was used and the solution temperature was thermostatically controlled at a desired value.

\subsection{Electrochemical Studies}

Electrochemical measurements were carried out by using an electrochemical work station, ivium instrument. A three electrode compartment cell was used for the electrochemical measurements. A saturated calomel electrode (SCE) and a platinum electrode were used as the reference and the counter electrode, respectively. The potentiodynamic current potential curves were recorded by polarizing the specimen to $-250 \mathrm{mV}$ cathodically and +250 $\mathrm{mV}$ anodically with respect to OCP at a scan rate of $1 \mathrm{mV} \cdot \mathrm{s}^{-1}$. Electrode potentials were measured with respect to SCE. The polarization studies were done immediately after the EIS studies on the same electrode without any further surface treatment. The AC impedance was performed in the frequency range from $20 \mathrm{kHz}$ to $200 \mathrm{~Hz}$ with a single amplitude of $10 \mathrm{mV}$.

\subsection{Quantum-Chemical Calculations Methodology}

Among quantum chemical methods for evaluation of corrosion inhibitors, density functional theory (DFT) has shown significant promise [7] and appears to be adequate for pointing out the changes in electronic structure responsible for inhibitory action. In order to explore the theoretical-experimental consistency, quantum chemical calculations were performed with complete geometry optimizations using standard Gaussian-03 software package [8]. Geometry optimization was carried out by B3LYP functional at the 6-31G (d) basis set [9] [10].

\section{Results and Discussion}

\subsection{Weight Loss Method}

The inhibiting efficiencies and corrosion rate with different concentrations ( $0.2 \mathrm{mM}$ to $1 \mathrm{mM})$ of $1 \mathrm{~A}$ and $1 \mathrm{~B}$ on mild steel in $1 \mathrm{M} \mathrm{H}_{3} \mathrm{PO}_{4}$ at different temperatures (303, 318, 323 and $328 \mathrm{~K}$ ) have been evaluated by weight loss measurements. The corresponding plots are given in Figure 1 and Figure 2. The results show that the corrosion rate decreases with increasing concentration of the inhibitor and hence the inhibition efficiency increases. Corrosion rate of mild steel increases with increase in temperature in both inhibited and uninhibited solutions. But 


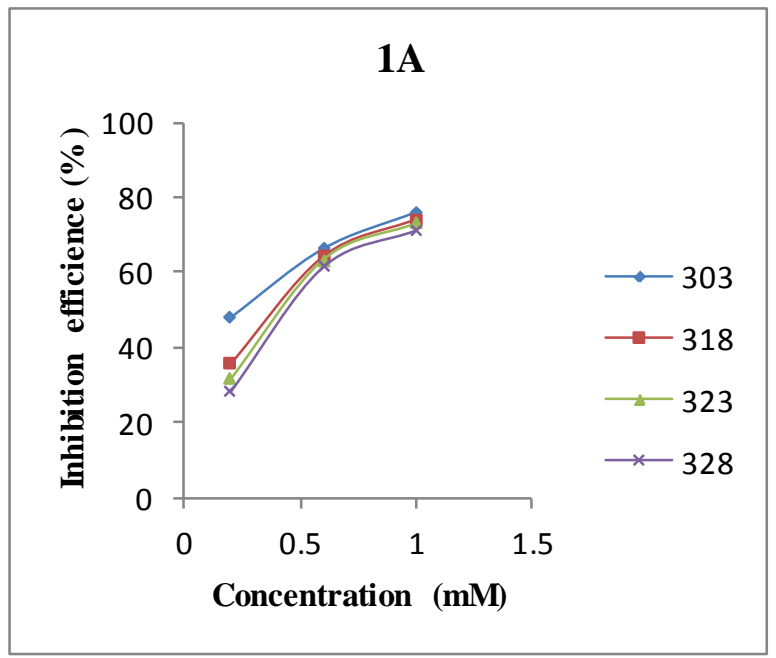

Figure 1. Plot of inhibition efficiency (\%) vs concentration $(\mathrm{mM})$ for the corrosion inhibition of $1 \mathrm{~A}$ on mild steel in $1 \mathrm{M}$ phosphoric acid $\left(\mathrm{H}_{3} \mathrm{PO}_{4}\right)$.

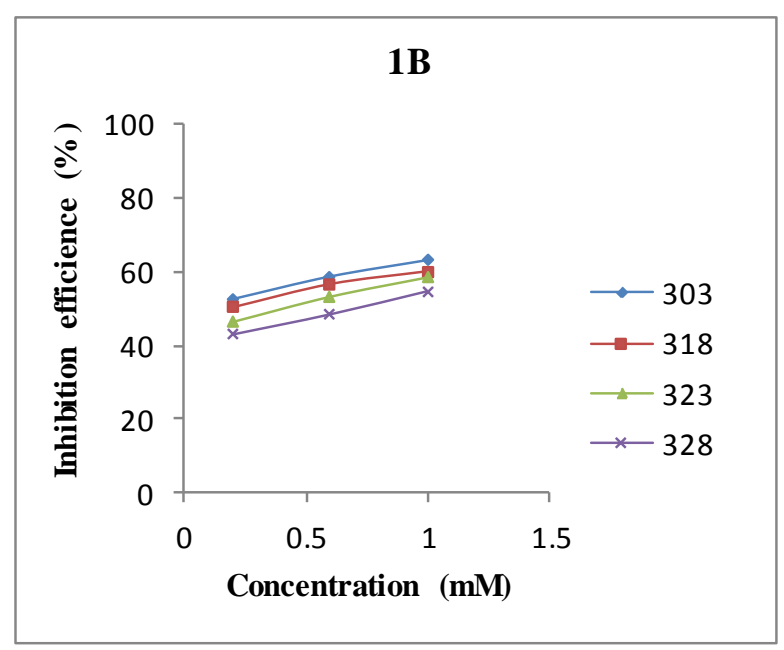

Figure 2. Plot of inhibition efficiency (\%) vs concentration (mM) for the corrosion inhibition of $1 \mathrm{~B}$ on mild steel in $1 \mathrm{M}$ phosphoric acid $\left(\mathrm{H}_{3} \mathrm{PO}_{4}\right)$.

the corrosion rate increases more rapidly with temperature in the absence of inhibitors.

\subsection{Adsorption Isotherms and Evaluation of Thermodynamic Parameters}

In order to obtained isotherm, the degree of surface coverage $(\theta)$ for the various concentrations of the inhibitor has been calculated. Various adsorption isotherm mentioned above were tested for both $1 \mathrm{~A}$ and $1 \mathrm{~B}$ compounds and among them Langmuir adsorption isotherm fits best for the experimental data of $1 \mathrm{~A}$ compound. Langmuir isotherm is given by

$$
C / \theta=1 / K_{\text {ads }}+C
$$

where $\theta$ is the degree of surface coverage, $C$ is the molar concentration for the bulk of the solution, $K_{a d s}$ is the equilibrium constant of the process of adsorption.

The Langmuir plot for 1A Compound fits neatly and the slope value is almost equal to unity (Table 1, Figure 3 and Figure 4). 


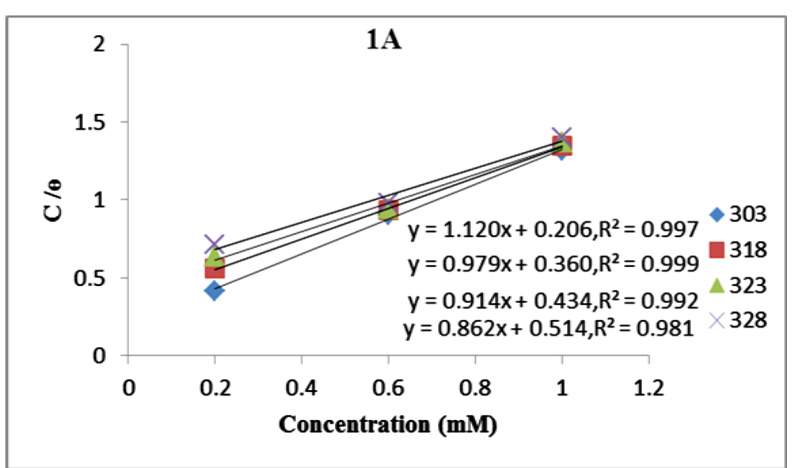

Figure 3. Langmuir plot for inhibitor $1 \mathrm{~A}$ in $1 \mathrm{M} \mathrm{H}_{3} \mathrm{PO}_{4}$.

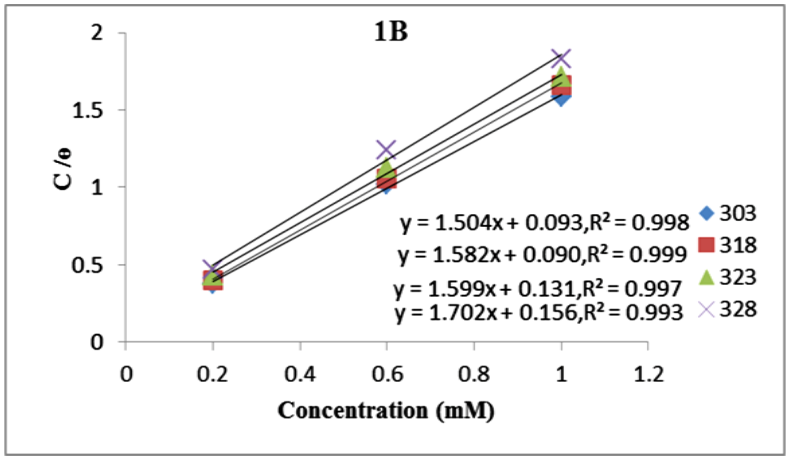

Figure 4. Langmuir plot for inhibitor $1 \mathrm{~B}$ in $1 \mathrm{M} \mathrm{H}_{3} \mathrm{PO}_{4}$.

Table 1. Some parameters from Langmuir isotherm model for mild steel in $1 \mathrm{M} \mathrm{H}_{3} \mathrm{PO}_{4}$.

\begin{tabular}{|c|c|c|c|c|c|}
\hline Inhibitor & $\begin{array}{c}\text { Temperature } \\
\text { (K) }\end{array}$ & Slope & $K$ & $R^{2}$ & $\begin{array}{c}\Delta G_{a d s}^{0} \\
(\mathbf{K J} / \mathbf{M o l})\end{array}$ \\
\hline \multirow{4}{*}{$1 \mathrm{~A}$} & 303 & 1.1207 & 4.8543 & 0.997 & 14.10 \\
\hline & 318 & 0.9797 & 2.7777 & 0.999 & 13.32 \\
\hline & 323 & 0.9146 & 2.3041 & 0.992 & 13.02 \\
\hline & 328 & 0.862 & 1.9455 & 0.981 & 12.76 \\
\hline \multirow{4}{*}{$1 \mathrm{~B}$} & 303 & 1.5040 & 10.7526 & 0.998 & 16.10 \\
\hline & 318 & 1.5827 & 11.111 & 0.999 & 16.98 \\
\hline & 323 & 1.5996 & 7.6335 & 0.997 & 16.02 \\
\hline & 328 & 1.7027 & 6.4102 & 0.993 & 16.07 \\
\hline
\end{tabular}

Langmuir plot for 1B compound also fits neatly. But the slope value of the Langmuir plot of 1B compound deviates considerably from unity. This deviation may be explained on the basis of interaction among adsorbed species on the surface of the metal. It has been postulated in the derivation of Langmuir isotherm equation that adsorbed molecules do not interact with one another, but this is not true in the case of large organic molecules having polar atoms or groups which can be adsorbed on the cathodic and anodic sites of the metal surface. Such adsorbed species interact by mutual repulsion or attraction. It is also possible that the inhibitor studied can adsorb on the anodic and cathodic sites resulting in deviation from unit gradient [11].

$K_{a d s}$ values obtained from Langmuir plots for $1 \mathrm{~A}$ and $1 \mathrm{~B}$ compound are included in Table 1 . These results confirm the suggestion that large values of $K_{\text {ads }}$ mean better inhibition efficiency of the inhibitors, $1 \mathrm{~A}$ and $1 \mathrm{~B}$. They are physically adsorbed on the metal surface, and that the strength of the adsorption decreases with tem- 
perature.

In Arrhenius equation, the activation energy $E_{a}$ was calculated from the slope obtained by plotting log corrosion rate vs 1000/T (Table 2). From the table $E_{a}$ in the presence of the both inhibitors are higher than those in the uninhibited acid solution. These results indicate physical adsorption.

From the transition equation plot of log W/T against 1/T for mild steel in $1 \mathrm{M} \mathrm{H}_{3} \mathrm{PO}_{4}$ solution the absence and presence of different concentration of $1 \mathrm{~A}$ and $1 \mathrm{~B}$ gave a straight line with slope equal to $\Delta H^{0}{ }_{a d s} / 2.303 R$ and intercept is $\log R / N h+\Delta S^{0}{ }_{a d s} / 2.303 R$. The positive values of $\Delta H^{0}$ ads and $\Delta S^{0}{ }_{a d s}$ obtained from the slope and intercept are included in Table 2. The positive value of $\Delta H_{\text {ads }}^{0}$ shows the endothermic nature of steel dissolution process. The positive value of $\Delta S^{0}{ }_{a d s}$ is higher for inhibited solution than that of uninhibited solution. This suggested that randomness occurred on going reactants to the activated complex.

\subsection{Electrochemical Impedance Studies}

The corrosion behaviors of mild steel in $1 \mathrm{M} \mathrm{H}_{3} \mathrm{PO}_{4}$ in the presence of $1 \mathrm{~A}$ and $1 \mathrm{~B}$ have been investigated by electrostatic impedance method at $30^{\circ} \mathrm{C}$. Nyquist plots were recorded. Impedance parameter curves as charge transfer resistance $\left(R_{t}\right)$ and double layer capacitance $\left(C_{d l}\right)$ are shown in Figure 5 and Figure 6.

The charge transfer resistance value increases with the increase in the inhibitor concentration, indicates that the efficiency of the inhibitor increases with concentration. Addition of inhibitor decreases the value of $C_{d l}$. Decrease in $C_{d l}$ is attributed to an increase in thickness of the electrical double layer with increase in concentration of the inhibitor.

\subsection{Potentiodynamic Polarization Studies}

Potentiodynamic polarization studies were carried out for the corrosion of mild steel in $1 \mathrm{M} \mathrm{H}_{3} \mathrm{PO}_{4}$ with/without inhibitors. The electrochemical parameters $E_{\text {corr }}$ (corrosion potential) and $I_{\text {corr }}$ (corrosion current density) were obtained by the extrapolation of anodic and cathodic Tafel slopes. Tafel constants $b_{a}$ and $b_{c}$ were obtained from the anodic and cathodic polarization curves, respectively (Figure 7 and Figure 8).

The $I_{\text {corr }}$ values of $1 \mathrm{M} \mathrm{H}_{3} \mathrm{PO}_{4}$ decreases with the addition of $1 \mathrm{~A}$ and $1 \mathrm{~B}$ and indicates the inhibiting nature. Moreover, there is a significant decrease in the value of both anodic and cathodic Tafel slopes with the increase in the inhibitor concentration showing that the addition of inhibitors modifies the mechanism of the hydrogen reduction as well as decreases the rate of anodic dissolution in all the cases. This means that inhibitors act by blocking both anodic and cathodic sites and behaves as mixed-type of acid corrosion inhibitors.

\subsection{Quantum Studies}

Quantum chemical calculations are confirmed to understand the inhibition mechanism. According to the Frontier Molecular Orbital theory (FMO), the chemical reactivity is a function of interaction between HOMO and

Table 2. Some Activation parameters of $\mathrm{H}_{3} \mathrm{PO}_{4}$ on mild steel.

\begin{tabular}{|c|c|c|c|c|c|c|}
\hline \multirow[b]{2}{*}{ Inhibitor } & \multirow[b]{2}{*}{ Concentration (mM) } & \multicolumn{2}{|c|}{ Arrhenius model } & \multicolumn{3}{|c|}{ Transition model } \\
\hline & & $E_{a}(\mathrm{KJ} / \mathrm{mol})$ & $\begin{array}{l}\text { Linear regression } \\
\text { coefficient (r) }\end{array}$ & $\Delta H^{0}{ }_{a d s} \mathrm{KJmol}^{-1}$ & $\begin{array}{c}\Delta S^{0}{ }_{a d s} \\
\mathrm{Jmol}^{-1} \mathbf{K}^{-1}\end{array}$ & $\begin{array}{l}\text { Linear regression } \\
\text { coefficient (r) }\end{array}$ \\
\hline \multirow{5}{*}{$1 \mathrm{~A}$} & Blank & 80.37 & 0.998 & 77.75 & 11.32 & 0.998 \\
\hline & 0.2 & 91.21 & 0.998 & 88.61 & 12.91 & 0.997 \\
\hline & 0.6 & 84.55 & 0.999 & 81.94 & 11.57 & 0.999 \\
\hline & 1 & 86.06 & 0.999 & 83.46 & 11.68 & 0.999 \\
\hline & Blank & 67.89 & 0.998 & 65.29 & 9.315 & 0.998 \\
\hline \multirow{3}{*}{$1 \mathrm{~B}$} & 0.2 & 73.62 & 0.996 & 71.01 & 9.970 & 0.995 \\
\hline & 0.6 & 74.52 & 0.995 & 71.89 & 10.06 & 0.994 \\
\hline & 1 & 74.09 & 0.997 & 71.49 & 9.945 & 0.997 \\
\hline
\end{tabular}




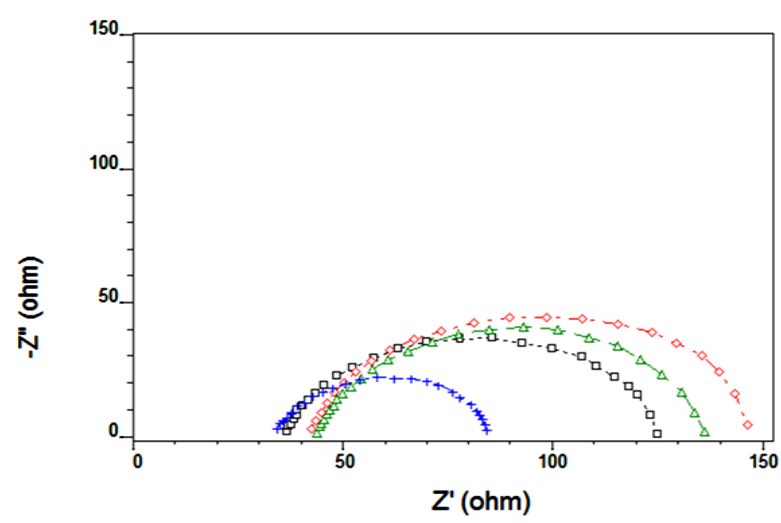

Figure 5. Nyquist diagram for mild steel in $1 \mathrm{M} \mathrm{H}_{3} \mathrm{PO}_{4}$ for selected concentrations of $1 \mathrm{~A}$.

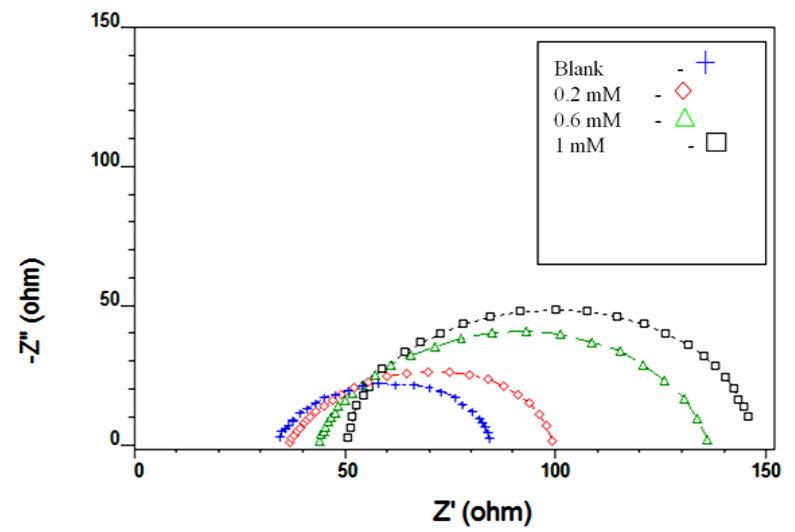

Figure 6. Nyquist diagram for mild steel in $1 \mathrm{M} \mathrm{H}_{3} \mathrm{PO}_{4}$ for selected concentrations of $1 \mathrm{~B}$.

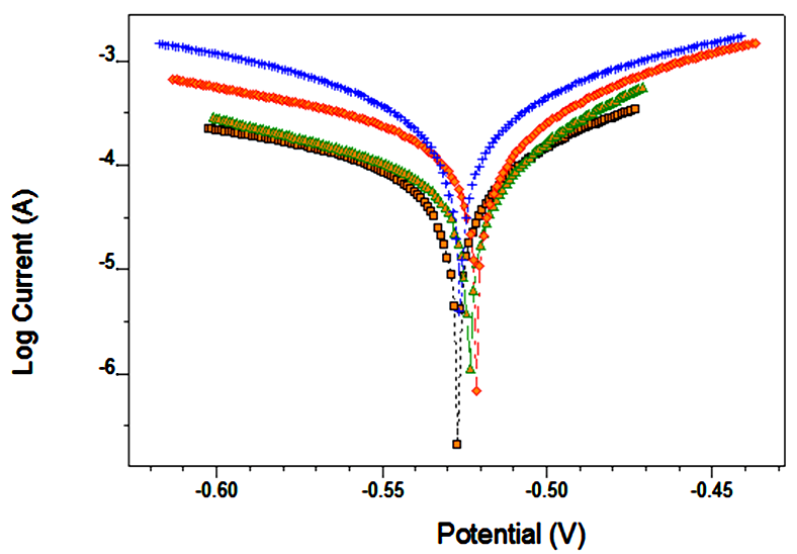

Figure 7. Polarization curves for mild steel in $1 \mathrm{M} \mathrm{H}_{3} \mathrm{PO}_{4}$ for selected concentrations of $1 \mathrm{~A}$.

LUMO levels of the reacting species [12]. The $E_{\text {Номо }}$ indicates the ability of the molecule to donate electrons to an appropriated acceptor with empty molecular orbitals and the lower is the value of $E_{L U M O}$ indicates its ability of the molecule to accept electrons [13] [14]. The higher is the value of $E_{\text {номо }}$ of the inhibitor, the greater is its ease of offering electrons to the unoccupied d-orbital of metal surface and the greater is its inhibition efficiency. The calculated $E_{\text {номо }}$ and $E_{L U M O}$ values of $1 \mathrm{~A}$ and $1 \mathrm{~B}$ are included in Table 3 . Analysis of the data shows that 
1B has lowest energy $E_{\text {Номо }}$ compared in the $1 \mathrm{~A}$. On the other hand, the $1 \mathrm{~A}$ destabilized the HOMO level by $0.0591 \mathrm{eV}$ to increase its donation to the metal surface and increases its tendency to adsorb on the metal surface and accordingly has high inhibition efficiency. The expectation is in good agreement with the experimental observations. It was found that the variation of the calculated LUMO energies among all investigated inhibitors is rulelessly, and the inhibition efficiency is misrelated with the changes of the $E_{L U M O}$, Table 3 . The optimization geometry structure of the inhibitors $1 \mathrm{~A}$ and $1 \mathrm{~B}$ were presented in Figure 9.

The energy gap, ( $\triangle E=E_{\text {НОмО }}-E_{L U M O}$ ) is an important parameter as a function of reactivity of the inhibitor molecule towards the adsorption on the metallic surface. As $\triangle E$ decreases the reactivity of the molecule in-

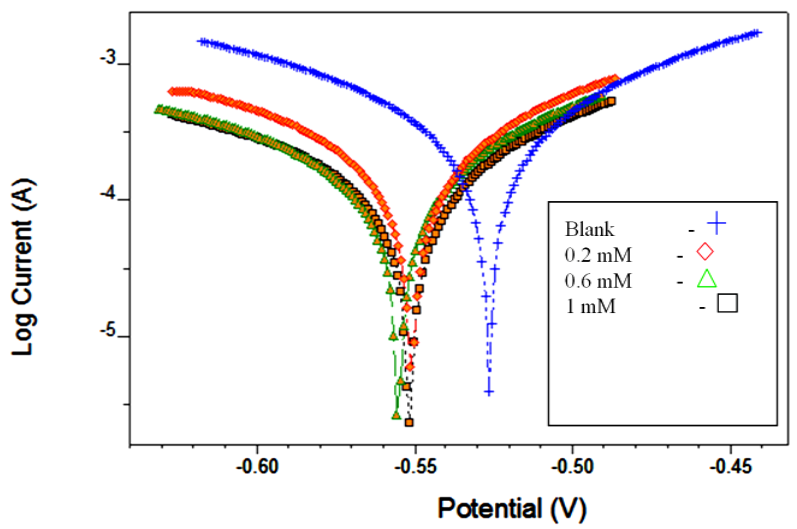

Figure 8. Polarization curves for mild steel in $1 \mathrm{M} \mathrm{H}_{3} \mathrm{PO}_{4}$ for selected concentrations of $1 \mathrm{~B}$.
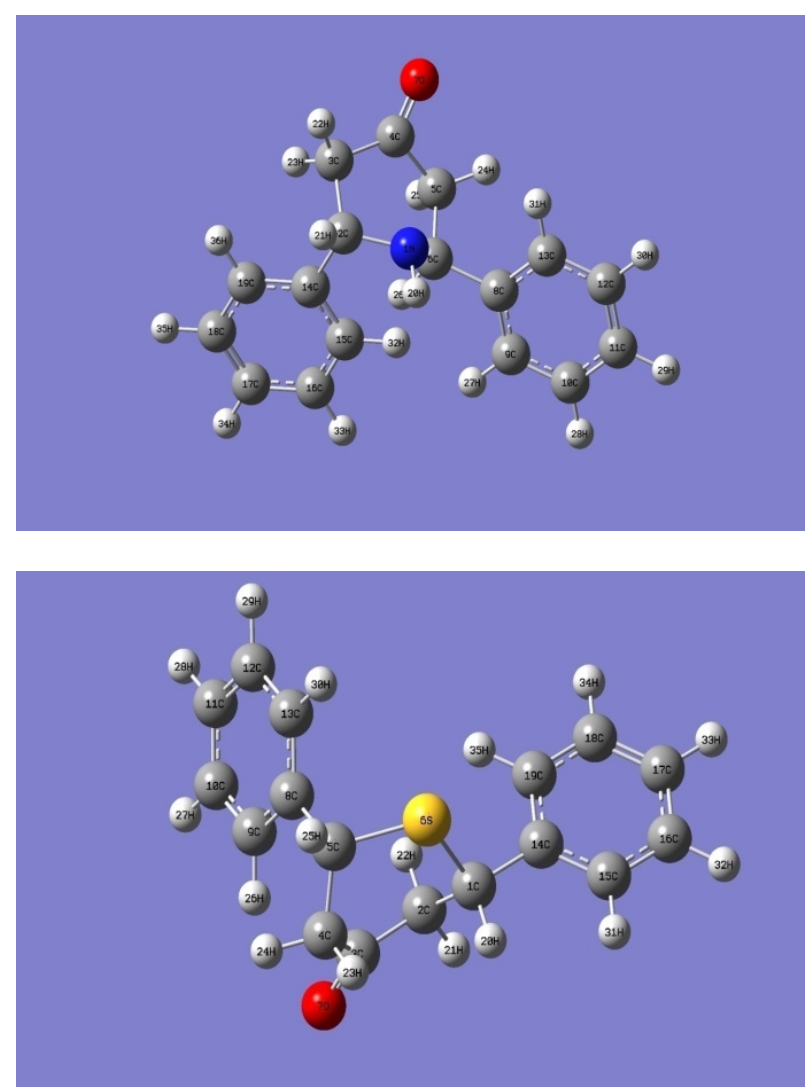

Figure 9. The optimized molecular structure of $1 \mathrm{~A}$ and $1 \mathrm{~B}$ using DFT at the B3LYP/6-31G (d) basis set level. 
Table 3. Quantum chemical descriptors for inhibitor 1A and 1B calculated using B3LYP/6-31G (d, p).

\begin{tabular}{|c|c|c|c|}
\hline S.No & Quantum chemical parameters & $1 \mathrm{~A}$ & 1B \\
\hline 1. & Total energy (au) & -787.8869 & -1130.8166 \\
\hline 2. & $E_{\text {Номо }}(\mathrm{eV})$ & -0.20833 & -0.2674 \\
\hline 3. & $E_{L U M O}(\mathrm{eV})$ & -0.01819 & -0.03256 \\
\hline 4. & $\triangle E(\mathrm{eV})$ & 0.19014 & 0.23484 \\
\hline 5. & Dipole moment $(\mu)$ & 3.6557 & 1.4350 \\
\hline 6. & Molecular formula & $\mathrm{C}_{17} \mathrm{H}_{17} \mathrm{NO}$ & $\mathrm{C}_{17} \mathrm{H}_{16} \mathrm{OS}$ \\
\hline 7. & Degrees of freedom & 102 & 99 \\
\hline 8. & Ionization potential (I) (eV) & 0.20833 & 0.2674 \\
\hline 9. & Electron affinity $(\mathrm{A})(\mathrm{eV})$ & 0.01819 & 0.03256 \\
\hline 10. & Electronegativity $(\chi)$ & 0.11326 & 0.14998 \\
\hline 11. & Chemical hardness $(\eta)$ & 0.09507 & 0.11742 \\
\hline 12. & Chemical softness $(S)$ & 10.5186 & 8.5164 \\
\hline 13. & Fraction of electrons transferred $(\triangle N)$ & 36.2193 & 29.1688 \\
\hline 14. & SCF & -787.886967589 & -1130.81668440 \\
\hline 15. & $\triangle E_{\text {Back-donation }}$ & -0.02376 & -0.029355 \\
\hline 16. & Electrophilicity index $(\omega)$ & 0.06748 & 0.09577 \\
\hline 17. & Chemical potential $(\mu)$ & -0.11326 & -0.14998 \\
\hline
\end{tabular}

creases leading to increase in the inhibition efficiency of the molecule [15]. Lower values of the energy difference will render good inhibition efficiency, because the energy to remove an electron from the last occupied orbital will be low [16]. A molecule with a low energy gap is more polarizable and is generally associated with the high chemical activity and low kinetic stability and is termed as soft molecule [17]. Soft molecule is more reactive than a hard molecule because a hard molecule has a large energy gap. The results as indicated in Table 3 shows that inhibitor $1 \mathrm{~A}$ has the lowest energy gap $(0.19014 \mathrm{eV})$, and inhibitor $1 \mathrm{~B}$ has highest energy gap $(0.23484 \mathrm{eV})$, this means that the $1 \mathrm{~A}$ molecule could have better performance as corrosion inhibitor (Figure 10(a), Figure 10(b)).

The dipole moment $(\mu)$ is another important electronic parameter, used for the prediction of the direction of a corrosion inhibition process. The dipole moment gives information on the polarity (hydrophobicity) in a bond of a molecule and therefore the electron distribution in the molecule [12] [18]. It is generally agreed that the adsorption of high polar compounds possessing high dipole moment on the metal surface should lead to better inhibition. In our study the dipole moment of the $1 \mathrm{~A}$ compound is $3.6557 \mathrm{eV}$ and $1 \mathrm{~B}$ compound is $1.4350 \mathrm{eV}$. The high value of the dipole moment of the $1 \mathrm{~A}$ inhibitor shows higher inhibition efficiency.

Ionization potential is a fundamental descriptor of the chemical reactivity of atoms and molecules. It is the amount of energy required to remove an electron from a molecule. The lower the ionization potential the easier it is to remove an electron from a molecule. High Ionization energy indicates high stability and chemical inertness and small Ionization energy indicates high reactivity of the atoms and molecules [19]. The ionization energy values of the inhibitors (1A and 1B) are $0.20833 \mathrm{eV} \& 0.2674 \mathrm{eV}$. The low ionization energy $0.20833 \mathrm{eV}$ of $1 \mathrm{~A}$ indicates the high inhibition efficiency.

Chemical hardness (global hardness) and softness parameter are related to the description of the hard and soft acid/base through the acid-base theory [19] [20]. It is apparent that the chemical hardness fundamentally signifies the resistance towards the deformation or polarization of the electro cloud of the atoms, ions or molecules under small perturbation of chemical reaction. A hard molecule has the least tendency to react while a soft molecule has high tendency to react. A hard molecule has a large energy gap and soft molecule has a small energy 


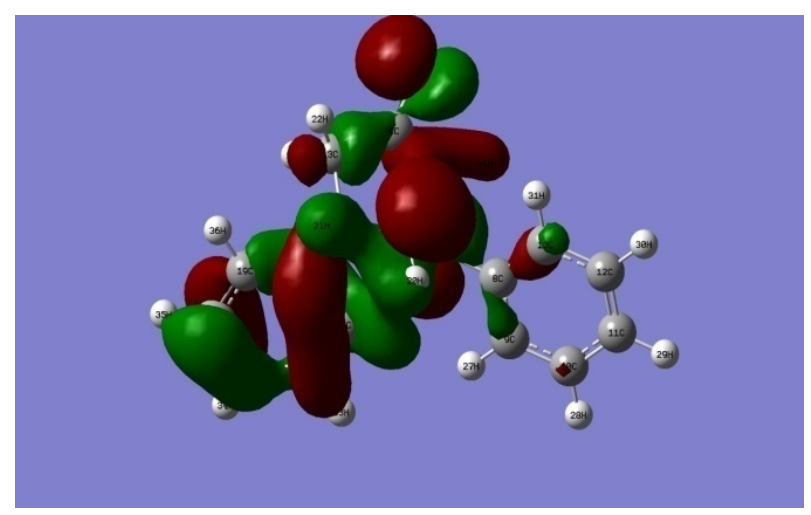

(a)

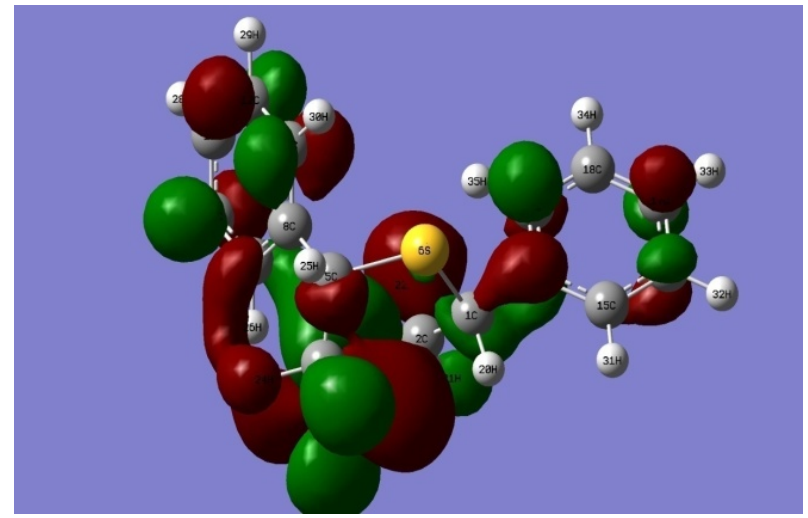

(b)

Figure 10. (a) The highest occupied molecular orbital (HOMO) and (b) lowest unoccupied molecular orbital (LUMO) of 1A using DFT at the B3LYP/6-31G (d) basis set level.

gap. In our present study $1 \mathrm{~A}$ has low hardness value $0.09507 \mathrm{eV}$ compared with the $1 \mathrm{~B}$ molecule $(0.11742 \mathrm{eV})$. Normally, the inhibitor with least value of global hardness (hence the highest value of global softness) is expected to have the highest inhibition efficiency. The order of softness is such that $1 \mathrm{~A}>1 \mathrm{~B}$. This trend is also in agreement with experimentally determined inhibition efficiency.

Electrophilicity values gives information on the nucleophilic or elecrophilic nature of the molecule. A high electrophilic value informs that the molecule has a high tendency to act as an electrophile while a low value of electrophilicity informs that the molecule has a high tendency to act as a nucleophile. A good, more reactive, nuceophile is characterized by lower value of $\mu, \omega$ and conversely a good electrophile is characterized by a high value of $\mu, \omega$. From the Table 1 the electrophilicity values is such that $1 \mathrm{~B}>1 \mathrm{~A}$. This trend also agrees with experimental results.

The fraction of electrons transferred $(\triangle N)$ is also an indication of the ability of the molecule to donate electrons and therefore to bind on the metal surface. It was calculated and tabulated in Table 3 . If $\Delta N<3.6$, the inhibition efficiency increases by increasing electron-donating ability of these inhibitors to donate electrons to the metal surface. The higher the value of $\Delta N$ is, the greater the tendency of a molecule to donate electrons to the electron poor species. In the case of corrosion inhibitors, a higher $\triangle N$ implies a greater tendency to interact with the metal surface (i.e., a greater tendency to adsorb on the metal surface). Thus, the highest fraction of electrons transferred (36.2193) is associated with the best inhibitor 1A that has the high inhibition efficiency, while the least fraction of electrons transferred (29.1688) is associated with the inhibitor $1 \mathrm{~B}$ that has the least inhibition efficiency.

According to the simple charge transfer model for donation and back-donation of charges recently proposed [21], an electronic back-donation process might be occurring governing the interaction between the inhibitor molecule and the metal surface. The concept establishes that if both processes occur, namely charge transfer to 
the molecule and back-donation from the molecule, the energy change is directly proportional to the hardness of the molecule, as indicated in the following expression.

$$
\Delta E_{\text {Back-donation }}=-\eta / 4
$$

The $\triangle E_{\text {Back-donation }}$ implies that when $\eta>0$ and $\triangle E_{\text {Back-donation }}<0$ the charge transfer to a molecule, followed by a back-donation from the molecule, is energetically favored. In this context, it is possible to compare the stabilization among inhibiting molecule, since there will be an interaction with the same metal. It is expected that it will decrease as the hardness increases.

The use of Mulliken population analysis to estimate the adsorption centers of inhibitors has been widely reported and it is mostly used for the calculation of the charge distribution over the whole skeleton of the molecule [22]-[27]. There is a general consensus by several authors that the more negatively charged heteroatom is the more, it can be adsorbed on the metal surface through donor-acceptor type reaction. The calculated Mulliken charges showed that there is more than one active center. Variation in the inhibition efficiency of the inhibitors depends on the presence of electronegative $\mathrm{O}, \mathrm{S}$ and $\mathrm{N}$ atoms as substituents in their molecular structure. The site of ionic reactivity could be estimated from the net charges on a molecule.

It may be noted that in 1A the ring nitrogen has more electronegative charge [N1 (-0.552812)] than the carbonyl oxygen [O7 (-0.445786)]. But 2,6-diphenylpiperdin-4-one exhibits boat conformation with carbonyl group and ring nitrogen para position to each other. So both " $\mathrm{N}$ " and "O" atoms acts as anchoring sites and get adsorbed onto the mild steel surface. The more positive nature of carbonyl carbon (C4) is adding support to this point. The phenyl rings which are in equatorial position try to have a weak interaction through the $\pi$ bonding electrons and hence the charge of both C8 and C14 which are away from mild surface decreases.

The C3 $(-0.361604)$ carbon atom is more negative than the other negative carbon atoms in the 1A molecule, due to electron-donating atoms. The presence of donor and acceptor atoms suggests the existence of both intra and inter-molecular hydrogen bonding in the crystalline phase.

In the case of $1 \mathrm{~B}$, sulfur atom has a positive charge, which shows the non-participating nature. 1B is expected to exist in chair conformations [28] and hence the participation of both carbonyl oxygen and ring "sulphur" in the adsorption process is ruled out. The positive charge of the sulphur atom shows the non-participation of "S" in adsorption process. Therefore, the inhibition efficiency is only due to carbonyl oxygen and hence inhibition efficiency is less than 1A. Therefore, the inhibition efficiency of $1 \mathrm{~B}$ is only due to oxygen and is comparatively less than $1 \mathrm{~A}$. A weak interaction between $\pi$ bonding electrons in the phenyl ring and metal surface is proved by the positive nature of C8 and C14. The experimental results obtained prove this observation to be true (Figure 11 and Figure 12). From the above discussions, it is clear that 1A with the two anchoring sites shows more inhibition efficiency than 1B. This observation is in good agreement with the experimental results Table 3.

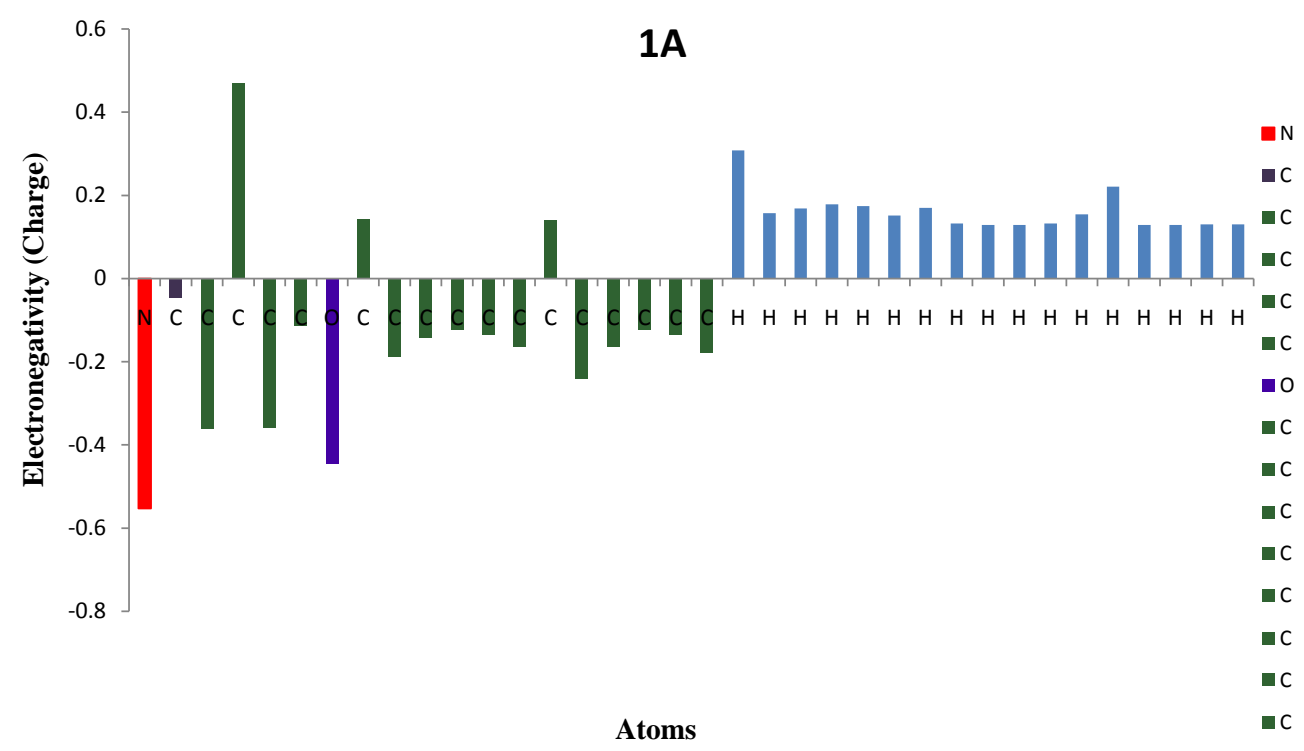

Figure 11. Mulliken charge of the 1A molecule. 


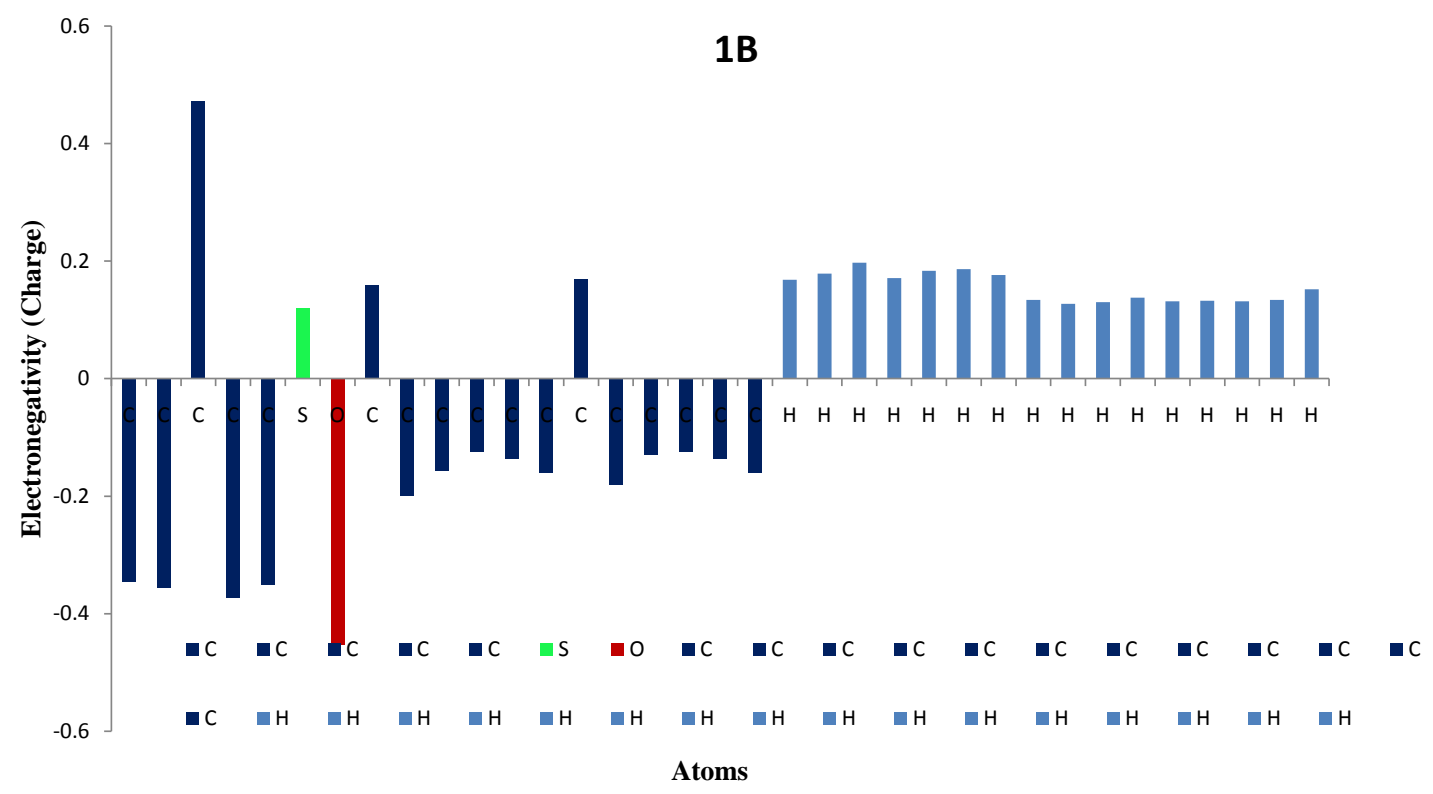

Figure 12. Mulliken charge of the 1B molecule.

\section{Conclusions}

- The inhibitors 1A and 1B shows a high efficiency towards corrosion of mild steel with increase in the concentration of inhibitor. The effect of temperature indicates that the inhibition efficiency decreases with rise in temperature.

- The activation energy $\left(E_{a}\right)$ is higher for inhibited acids than for uninhibited acids showing the temperature dependence of inhibition efficiency. The negative value of $\Delta H^{*}$ and $\Delta S^{*}$ indicates exothermic reaction.

- The negative value of $\Delta G^{0}$ ads indicates the spontaneous adsorption of the inhibitor. The adsorption of the inhibitor follows Langmuir and El-Awady adsorption isotherm.

- Potentiodynamic polarization curves indicate that all the inhibitors behave as mixed type inhibitors.

- $1 \mathrm{~A}$ has the highest inhibition efficiency because it had the highest HOMO energy and $\triangle N$ values and lowest energy gap it was most capable of offering electrons and it could have a better performance as corrosion inhibitor.

- The parameters hardness $(\eta)$, softness $(S)$, dipole moment $(\mu)$, electron affinity $(A)$, ionization potential $(I)$, the absolute electronegativity $(\chi)$, the fraction of electron transferred $(\triangle N)$ confirms the inhibition efficiency in order of $1 \mathrm{~A}>1 \mathrm{~B}$.

Good correlation between the theoretical and experimental data which confirms the reliability of the quantum chemical methods to study the inhibition of corrosion of metal surface.

\section{References}

[1] Udhayakala, P., Jayanthi, A. and Rajendiran, T.V. (2011) Adsorption and Quantum Chemical Studies on the Inhibition Potentials of Some Formazan Derivatives. Der Pharma Chemica, 3, 528-539.

[2] Obi-Egbedi, N.O., Obot, I.B., El-Khaiary, M.I., Umoren, S.A. and Ebsnso, E.E. (2011) Computational Simulation and Statistical Analysis on the Relationship Between Corrosion Inhibition Efficiency and Molecular Structure of Some Phenanthroline Derivatives on Mild Steel Surface. International Journal of Electrochemistry, 6, 5649.

[3] Bereket, G., Ogretir, C. and Yurt, A. (2001) Quantum Mechanical Calculations on Some 4-Methyl-5-Substituted Imidazole Derivatives as Acidic Corrosion Inhibitor for Zinc. Journal of Molecular Structure (THEOCHEM), 571, 139145. http://dx.doi.org/10.1016/S0166-1280(01)00552-8

[4] Awad, M.K. (2004) Semiempirical Investigation of the Inhibition Efficiency of Thiourea Derivatives as Corrosion Inhibitors. Journal of Electroanalytical Chemistry, 567, 219-225. http://dx.doi.org/10.1016/j.jelechem.2003.12.028

[5] Awad, M.K., Mahgoub, F.M. and El-Iskandrani, M.M. (2000) Theoretical Studies of the Effect of Structural Parameters on the Inhibition Effciencies of Mercapto-1,2,4-Triazoline Derivatives. Journal of Molecular Structure (THEOCHEM), 
531, 105-117. http://dx.doi.org/10.1016/S0166-1280(00)00437-1

[6] Balasubramanian, M. and Padma, N. (1963) Studies on Conformation-I-Preparation and Stereochemistry of Some 4Piperidinols. Tetrahedron, 19, 2135-2143. http://dx.doi.org/10.1016/0040-4020(63)85028-0

[7] Udhayakala, P., Rajendiran, T.V. and Gunasekaran, S. (2012) Theroetical Evaluation on the Efficiencies of Some Flavonoids as Corrosion Inhibitors on Copper. Journal of Chemical, Biological and Physical Sciences, Section A: Chemical Sciences, 2, 1151.

[8] Lopez, N. and Illas, F. (1998) Ab Initio Modeling of the Metal-Support Interface: The Interaction of Ni, Pd and Pt on MgO(100). Journal of Physical Chemistry B, 102, 1430. http://dx.doi.org/10.1021/jp972626q

[9] Frisch, M.J., Trucks, G.W., Schlegel, H.B., et al. (2003) Gaussian 03. Gauussian, Inc., Pittsburgh.

[10] Parr, R.G. and Yang, W. (1989) Density Functional Theory of Atoms and Molecules. Oxford University Press, New York.

[11] Ebenso, E.E. and Obot, I.B. (2010) Inhibitive Properties, Thermodynamic Characterization and Quantum Chemical Studies of Secnidazole on Mild Steel Corrosion in Acidic Medium. International Journal of Electrochemical Science, 5, 2012-2035.

[12] Gece, G. (2008) The Use of Quantum Chemical Methods in Corrosion Inhibitor Studies. Corrosion Science, 50, 29812992. http://dx.doi.org/10.1016/j.corsci.2008.08.043

[13] Zhang, D.Q., Gao, L.W. and Zhou, G.D. (2004) Inhibition of Copper Corrosion in Aerated Hydrochloric Acid Solution by Heterocyclic Compounds Containing a Mercapto Group. Corrosion Science, 46, 3031-3040. http://dx.doi.org/10.1016/j.corsci.2004.04.012

[14] Rahman, H.H.A., Moustafa, A.H.E. and Awad, M.K. (2012) Potentiodynamic and Quantum Studies of Some Amino Acids as Corrosion Inhibitors for Copper. International Journal of Electrochemical Science, 7, 1266-1287.

[15] Awad, M.K., Mustafa, M.R. and Elnga, M.M.A. (2010) Computational Simulation of the Molecular Structure of Some Triazoles as Inhibitors for the Corrosion of metal Surface. Journal of Molecular Structure: THEOCHEM, 959, 66-74. http://dx.doi.org/10.1016/j.theochem.2010.08.008

[16] Obot, I.B., Obi-Egbedi, N.O. and Umoren, S.A. (2009) Adsorption Characteristics and Corrosion Inhibitive Properties of Clotrimazole for Aluminium Corrosion in Hydrochloric Acid. International Journal of Electrochemical Science, 4, 863-877.

[17] Fleming, I. (1976) Frontier Orbitals and Organic Chemical Reactions. John Wiley and Sons, New York.

[18] Ebenso, E.E., Isabiye, D.A. and Eddy, N.O. (2010) Adsorption and Quantum Chemical Studies on the Inhibition Potentials of Some Thiosemicarbazide for the Corrosion of Mild Steel in Acidic Medium. International Journal of Molecular Sciences, 11, 2473-2498. http://dx.doi.org/10.3390/ijms11062473

[19] Pearson, R.G. (1986) Absolute Electronegativity and Hardness Correlated with Molecular Orbital Theory. Proceedings of the National Academy of Sciences of the United States of America, 83, 8440-8441. http://dx.doi.org/10.1073/pnas.83.22.8440

[20] Kabanda, M.M., Shukla, S.K., Singh, A.K., Murulana, L.C. and Ebenso, E.E. (2012) Electrochemical and Quantum Chemical Studies on Calmagite and Fast Sulphone Black F Dyes as Corrosion Inhibition for Mild Steel in Hydrochloric Medium. International Journal of Electrochemical Science, 7, 8813-8831.

[21] Gómez, B., Likhanova, N.V., Domínguz-Aguilar, M.A., Martínez-Palou, R., Vela, A. and Gásquez, J. (2006) Quantum Chemical Study of the Inhibitive Properties of 2-Pyridyl-Azoles. The Journal of Physical Chemistry B, 110, 8928-8934. http://dx.doi.org/10.1021/jp057143y

[22] Hasanov, R., Sadikoğlu, M. and Bilgiç, S. (2007) Electrochemical and Quantum Chemical Studies of Some Schiff Bases on the Corrosion of Steel in $\mathrm{H}_{2} \mathrm{SO}_{4}$. Applied Surface Science, 253, 3913-3921. http://dx.doi.org/10.1016/j.apsusc.2006.08.025

[23] Allam, N.K. (2007) Thermodynamic and Quantum Chemistry Characterization of the Adsorption of Triazole of Trizole Derivatives during Muntz Corrosion in Acidic and Neutral Solutions. Applied Surface Science, 253, 4570-4577. http://dx.doi.org/10.1016/j.apsusc.2006.10.008

[24] Özcan, M., Dehri, I. and Erbil, M. (2004) Organic Sulphur-Containing Compounds as Corrosion Inhibitors for Mild Steel in Acidic Media: Correlation between Inhibition Efficiency and Chemical Structure. Applied Surface Science, 236, 155-164. http://dx.doi.org/10.1016/j.apsusc.2004.04.017

[25] Roque, J.M., Pandiyan, T., Cruz, J. and García-Ochoa, E. (2008) DFT and Electrochemical Studies of Tris(benzimidazole-2-ylmethyl)amine as an Efficient Corrosion Inhibitor for Carbone Steel Surface. Corrosion Science, 50, 614-624. http://dx.doi.org/10.1016/j.corsci.2007.11.012

[26] Kandemirli, F. and Sagdinc, S. (2007) Theoretical Study of Corrosion Inhibition of Amides and Thiosemicarbazones. Corrosion Science, 49, 2118-2130. http://dx.doi.org/10.1016/j.corsci.2006.10.026 
[27] Fukui, K. (1975) Theory of Orientation and Stereoselection. Springer-Verlag, New York. http://dx.doi.org/10.1007/978-3-642-61917-5

[28] Noller, C.R. and Baliah, V. (1948) The Preparation of Some Piperidone Derivatives by the Mannich Reaction. Journal of the American Chemical Society, 70, 3853-3855. http://dx.doi.org/10.1021/ja01191a092 
Scientific Research Publishing (SCIRP) is one of the largest Open Access journal publishers. It is currently publishing more than 200 open access, online, peer-reviewed journals covering a wide range of academic disciplines. SCIRP serves the worldwide academic communities and contributes to the progress and application of science with its publication.

Other selected journals from SCIRP are listed as below. Submit your manuscript to us via either submit@scirp.org or Online Submission Portal.
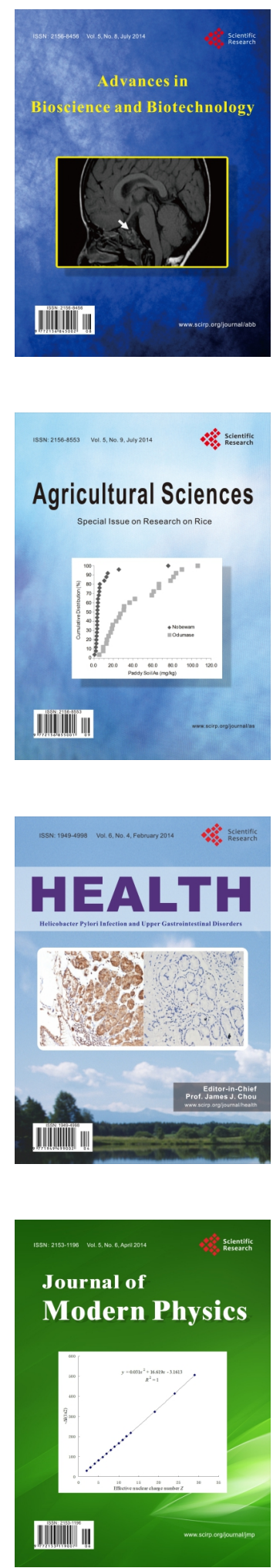
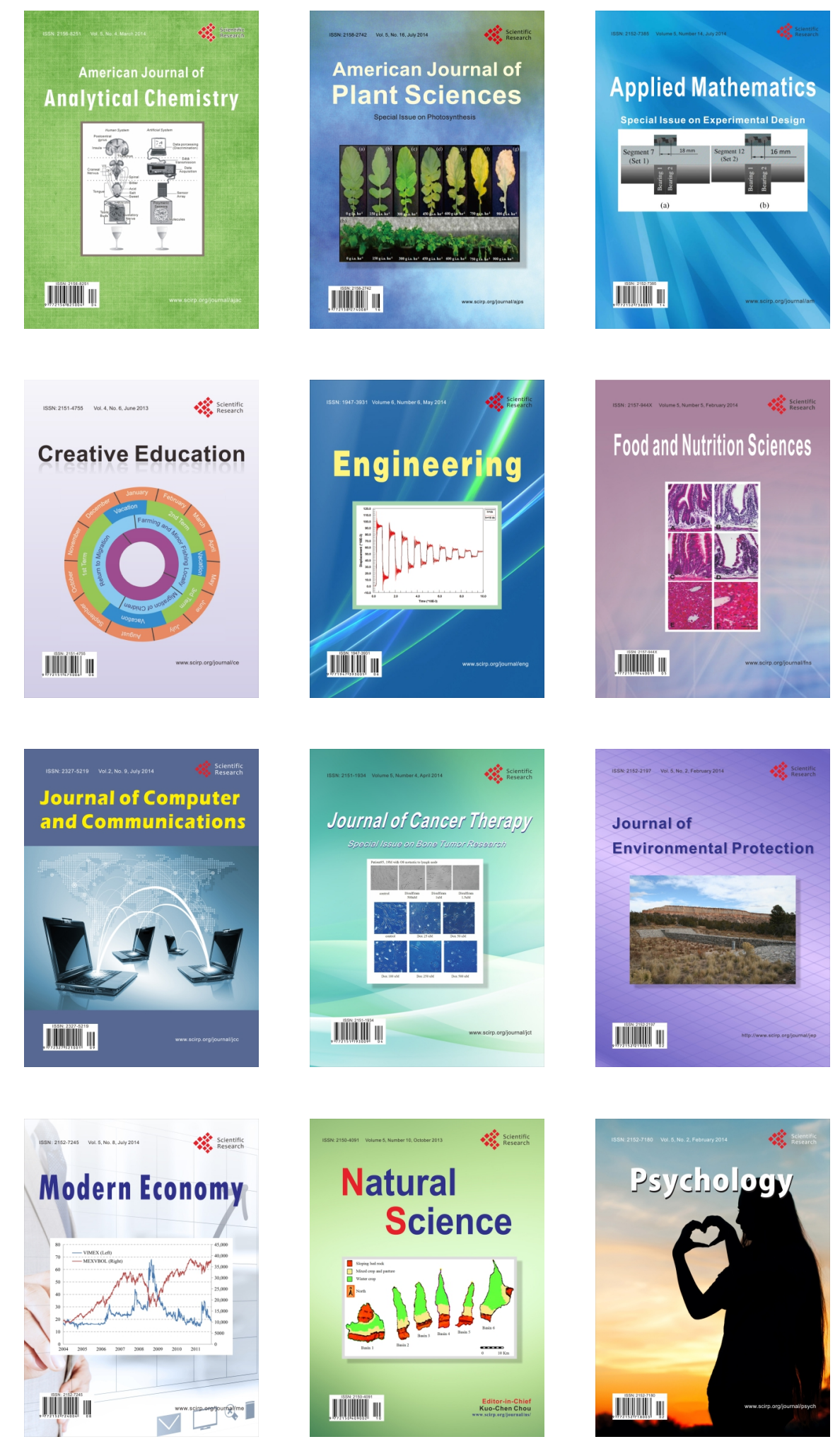